

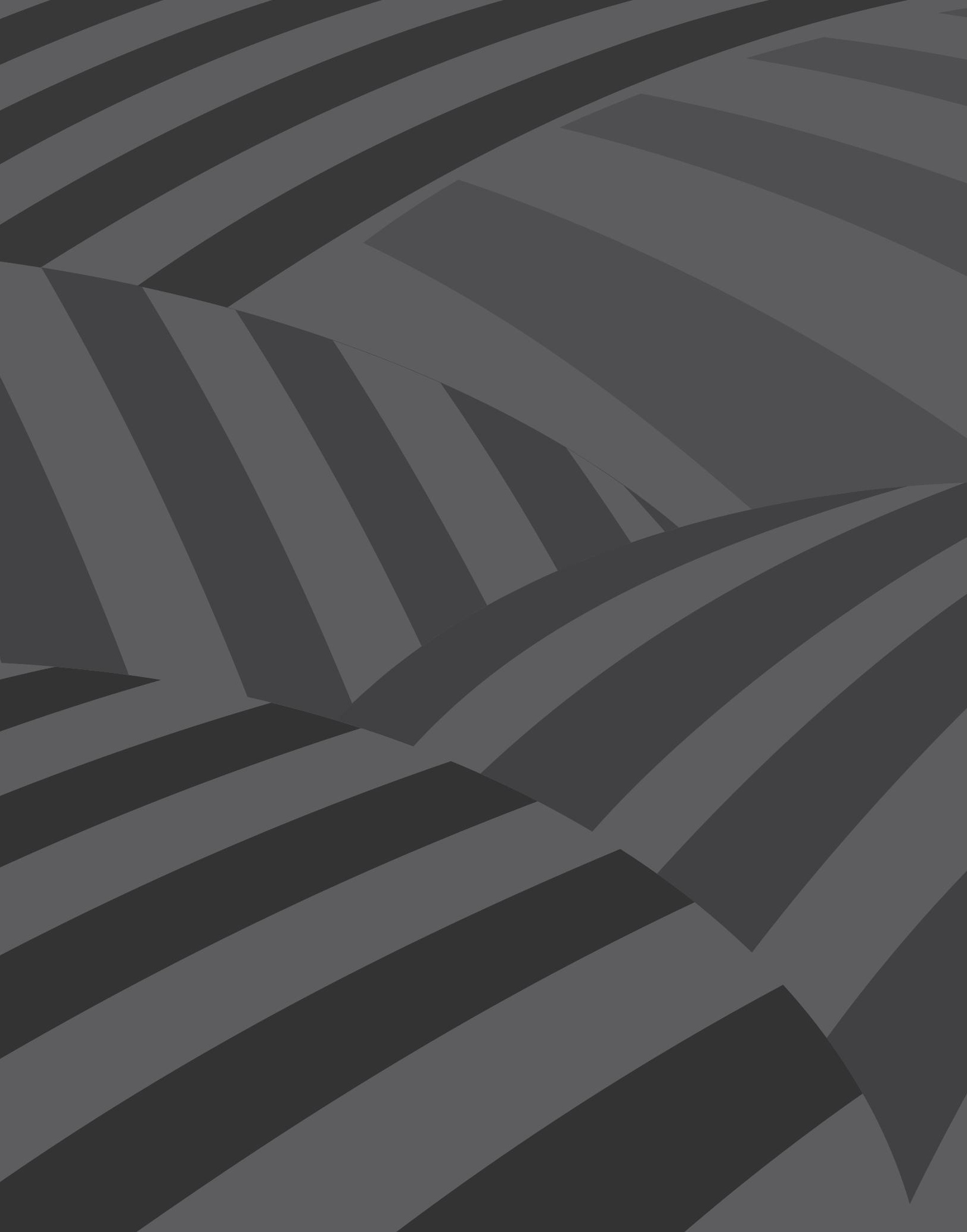




\title{
Hacer memoria de la defensa de los presos políticos de México desde una perspectiva soslayada
}

\author{
Por Anahi Morales Hudon*, Adriana Pozos Barcelata**
}

Resumen: Las memorias de los movimientos sociales son resultado de un proceso colectivo, sin embargo, la subjetividad de quienes fueron partícipes y protagonistas parte de una mirada única. La defensa de los derechos humanos en México tiene sus orígenes en el marco del movimiento armado socialista. Surgió por la iniciativa de mujeres familiares de presos políticos en el contexto de la llamada Guerra Sucia (1964-1982). En este artículo, rescatamos esta génesis y abordamos los orígenes y el proceso organizativo del primer Comité de Familiares de Presos, Perseguidos y Exiliados Políticos a partir de una entrevista en profundidad con una de sus fundadoras, Blanca Hernández. El rescate de la memoria de este comité hasta ahora soslayado, pionero en la defensa de los derechos humanos en México, permite destacar su rol histórico y resaltar las memorias de una de sus líderes y pioneras a partir de sus vivencias en diversas luchas subyacentes. Con este fin, se abordan tres dimensiones clave del origen y la trayectoria de este comité: el contexto sociopolítico en el cual surgió; las dinámicas que están detrás de la formación de estructuras de movilización y las estrategias de acción que desarrollaron, así como las dinámicas de género latentes y, finalmente, el marco de significación con base en el cual se movilizaron: los derechos humanos.

Palabras clave: memoria subjetiva, presos políticos, comité de familiares, guerra sucia, México.

\section{A Forgotten Narrative: Retracing Memories of the Defense of Mexican Political Prisoners}

Abstract: Social movements' memories are the result of a collective process, while simultaneously the subjectivity of its members and protagonists emerge from unique perspectives. The defense of human rights in Mexico originated in the context of the socialist armed movement. It emerged as an initiative instigated by female relatives of political prisoners during the so-called Dirty War (1964-1982). In this article, we address the origins and organizational process of the first committee of relatives of the political prisoners, the persecuted and the exiled through an in-depth interview with one of its founders, Blanca Hernández. By reconstructing the memory of this pioneering committee in the defense of human rights in Mexico, this paper uncovers

* Université Saint-Paul. Correo: amorales@ustpaul.ca

** Université du Québec à Montréal. Correo: astridpozos@gmail.com 
the committee's historical role while underlining the memories of one of its pioneering leaders through her experiences in various struggles. We discuss three central dimensions of the origin and trajectory of this committee: the sociopolitical context in which it emerged; the dynamics behind the mobilization structures and strategies of collective action, as well as the underlying gender dynamics; and finally, the frame on which the movement mobilized, that of human rights.

Keywords: subjective memories, political prisoners, committee of relatives, dirty war, Mexico.

Cómo citar este artículo: Morales Hudon, Anahi y Pozos Barcelata, Adriana (2019). Hacer memoria de la defensa de los presos políticos de México desde una perspectiva soslayada. Revista Controversia, $213,341-372$.

Fecha de recepción: 12 de marzo de 2019

Fecha de aprobación: 1 de mayo de 2019

\section{Introducción ${ }^{1}$}

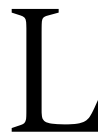

a defensa de los derechos humanos en México comenzó a principios de la década de 1970, pero se afirma con frecuencia que el primer comité prodefensa de los presos, perseguidos y desaparecidos políticos en México fue el liderado por Rosario Ibarra de Piedra, madre de Jesús Piedra Ibarra, desaparecido en Monterrey, Nuevo León, el 18 de abril de 1975 (Hincapié Jiménez y López Pacheco, 2016; López Pacheco, 2015; Maier, 2001; Rodríguez Ramírez, 2011). Sin embargo, antes de este existió otro comité, nacional también, que ha sido menos visibilizado, el cual fue pionero en la defensa de los derechos humanos y marcó la pauta para las organizaciones posteriores.

Este Comité de Familiares de Presos, Perseguidos y Exiliados Políticos surgió por iniciativa de un grupo de mujeres que actuaba principalmente a nivel local en la capital del país. En ese sentido, si bien es cierto que la represión hacia los grupos disidentes que tomaron las armas en

1 Las autoras agradecen a Geneviève Lessard y Philippe Dufort por sus valiosos comentarios a una versión preliminar del manuscrito. 
el marco de la llamada guerra sucia (1964-1982) ha sido subestudiada, el análisis del movimiento social que se originó en su defensa ha sido prácticamente soslayado. Este artículo le otorga un sitio central a los inicios de este movimiento por los derechos humanos en México, a través de la subjetividad expresada en la narrativa de una de sus pioneras, Blanca Hernández, recopilada a partir de diversas sesiones de una entrevista en profundidad practicadas en febrero, marzo y diciembre de $2017^{2}$.

Interesa destacar que, en un marco de particular represión frente a toda sospecha de acción contra el régimen o de su denuncia, en el Comité no guardaron una memoria documental de su acción ni de sus procesos, por lo que resulta indispensable rescatar esa memoria oral, sobre todo en la actualidad, cuando estas violencias de Estado retoman fuerza en el marco de la crisis de derechos humanos por la que atraviesa México desde 2006.

La elección de una sola entrevista en profundidad, con una actriz clave de este proceso, nos permite adentrarnos en la construcción de esta subjetividad colectiva, narrada en primera persona, pero siempre en diálogo con un sujeto colectivo representado por un «nosotras». Tomar en cuenta, además, la dimensión de género, faculta el análisis de las «tácticas de des-sujeción», las cuales consisten en las prácticas de quienes participan en los movimientos sociales, que «logran deslizar las fronteras de inteligibilidad que limitan su identidad como activistas» (Florez, 2007, p. 141). De acuerdo con Florez, dichas tácticas consisten en un ejercicio continuo que supone tomar distancia de manera intermitente de la identidad en torno a la que se articulan las y los diferentes actores en la lucha para incorporar demandas vinculadas a otras marcas identitarias y subjetivas (p. 145).

2 La investigación presentada para este artículo fue aprobada por el comité de ética de la Universidad Saint-Paul, Ottawa. 
En efecto, tal como se analiza a lo largo del texto, la manera en que las mujeres del comité hacían frente a la tensión subyacente de las dinámicas de género en el movimiento, con quienes defendían, pero también con sus aliados estratégicos, se podría analizar como una de estas «tácticas de des-sujeción». Esto se debe a que una batalla paralela al objetivo primario del comité que era pugnar por la liberación de los presos políticos y la defensa de los derechos humanos, eran las relaciones de género. Entonces, si la mayoría de los movimientos sociales en las décadas de 1960 y 1970 estuvo liderada por hombres, la defensa de los derechos humanos en específico estuvo liderada por mujeres, siempre atravesada por las dinámicas de género, en las que de manera más amplia estaban insertas. El artículo destaca así el papel central que jugaron las mujeres en la conformación de esta defensa y aborda una dimensión que ha sido poco estudiada en la literatura, que recoge la historia y trayectoria de la defensa de los derechos humanos en México: el sexismo, del cual no estuvieron exentas sus militantes, y cómo lo enfrentaron ellas.

Con este objetivo se estudian tres dimensiones clave para comprender el origen y la trayectoria del Comité. En un primer momento, analizaremos el contexto sociopolítico en el cual surgió este proceso de organización, un contexto marcado por una represión generalizada por parte del Estado hacia los movimientos subversivos. Este análisis, particularmente de las condiciones de detención en las cuales se encontraban muchas y muchos de los presos políticos de la época, facilitará la comprensión de la situación contra la cual se movilizaron las mujeres que conformaron el Comité. En un segundo momento, expondremos las dinámicas detrás del proceso organizativo y las estrategias de acción que desarrollaron sus integrantes. Analizaremos cómo, luego de varios años de visitas a prisión y al darse cuenta de que los procesos de sus compañeros y familiares no avanzaban, las fundadoras decidieron organizarse de manera colectiva. En un tercer momento, estudiaremos cómo el Comité recurrió al discurso de derechos humanos como el marco de significación con base en el cual se movilizaron. 


\section{Contexto de movilización}

Esta primera sección brinda un análisis del contexto sociopolítico en el cual surgió el primer comité de defensa de prisioneros políticos; este contexto estuvo marcado por fuertes movilizaciones, pero también determinado por la acción represiva que el Estado infligió a los miembros del movimiento armado socialista mexicano. Las condiciones en las que los presos políticos permanecían en detención, además de ilegales, eran infrahumanas y estos eran constantemente sometidos a tratos crueles, inhumanos y degradantes, lo que fue el detonador del primer comité de familiares que organizarían su defensa. El objetivo era exigir un debido proceso como sujetos individuales, pero en el marco de una defensa colectiva. La comprensión de este contexto nos permitirá situar de una mejor manera la mirada de las mujeres del Comité de Familiares de Presos, Exiliados y Perseguidos Políticos sobre las actividades que emprendieron en el marco de su acción política.

\section{Contexto político}

A finales de la década de 1960, debido a varios factores, emergieron diversos movimientos subversivos a lo largo del continente, tanto en el medio rural como urbano. La estabilidad económica de las clases medias urbanas y el mayor acceso a la educación, aunado al entusiasmo que generó la revolución cubana, propiciaron una importante revolución cultural en varios países del mundo, incluido México. Existen varios casos emblemáticos de esta revolución cultural protagonizada por los movimientos de 1968, por ejemplo, en Estados Unidos, las protestas masivas de la población contra la guerra de Vietnam; en Checoslovaquia, la primavera de Praga; en Francia lo que se conoció como el Mayo francés; y en México, por supuesto, la masiva movilización de estudiantes que concluyó con la matanza en la plaza de Tlatelolco el 2 de octubre de 1968. Esta última detonó el proceso organizativo de las guerrillas urbanas con participación de estudiantes universitarios, las cuales formaron parte del movimiento armado 
socialista mexicano y se expandieron en la década siguiente (Aguayo, 2014; Castellanos, 2009; Scherer y Monsivais, 1999).

En México estas movilizaciones tomaron lugar en un contexto marcado por condiciones de marginación y explotación en el medio rural en particular. A finales de los años cincuenta, Rubén Jaramillo fue uno de los primeros en llamar a tomar las armas para reclamar mejores salarios para los jornaleros cañeros, la repartición de tierras al campesinado, la disolución de monopolios y la expropiación de la industria básica, movimiento que fue brutalmente reprimido por la presidencia de Adolfo López Mateos (1958-1964) (Camacho, 2018; Padilla, 2008). Años más tarde, estas mismas condiciones estructurales y la inequidad del acceso a la educación, además de los abusos de poder del magisterio y de la clase política, fueron las condiciones que llevaron a Pablo Gómez Ramírez (1926-1965), Arturo Gámiz García (1940-1965), Genaro Vásquez Rojas (1931-1972) y Lucio Cabañas Barrientos (1936-1974) —-todos profesores rurales-, a ser de los primeros en llamar a la toma de las armas con la esperanza de cambiar las condiciones estructurales de la pobreza y la sujeción del campesinado.

En el medio urbano y, particularmente, en las grandes ciudades, las recientes matanzas de estudiantes -2 de octubre de 1968 y Jueves de Corpus de 1971 - habrían contribuido a motivar la formación de diversos grupos guerrilleros dirigidos principalmente por estudiantes universitarios quienes también pretendían incidir en las condiciones estructurales de inequidad social (Aguayo, 2014; Castellanos, 2009; Scherer y Monsivais, 1999). De esta manera, tanto en el medio rural como en el medio urbano, en la primera mitad de la década de 1970, los grupos que tomaron la vía armada se multiplicaron y dieron lugar a más de una treintena en el país (Castellanos, 2009, p. 425), entre las cuales destaca la que fue la más grande organización de la guerrilla urbana, la Liga Comunista 23 de septiembre (la Liga), fundada en 1973 en Guadalajara por dirigentes de diferentes grupos guerrilleros de diversas ciudades como Guadalajara, Sinaloa, Chihuahua, Monterrey, México y 
Baja California. A su vez, la Liga estaba dividida en diferentes brigadas: la Brigada Genaro Vásquez en Zihuatanejo, la Brigada Revolucionaria Emiliano Zapata en Oaxaca y la Brigada Roja en la capital del país (pp. 425-431). Esta última inspiraría el nombre, por contraposición, del grupo cuasi-paramilitar del Estado, la Brigada Blanca, que tendría por objetivo combatir a la Liga, que se convirtió en una maquinaria de represión contrainsurreccional (Aguayo, 2014; Castellanos, 2009; Eco, 2012; López de la Torre, 2013; Scherer y Monsivais, 1999).

\section{Represión de los movimientos sociales y presos políticos}

El gobierno mexicano se sumó a la tentativa continental de frenar los movimientos sociales considerados como subversivos vinculados con la ideología comunista. En ese marco, se adoptaron doctrinas militares como la del enemigo interno, la cual establecía que el enemigo era cualquier persona que simpatizara con la ideología comunista y que la subversión no se limitaba a la insurrección armada, sino que abarcaba también a sectores de la sociedad civil. Esta doctrina llegó a designar como enemigo interno «cualquier tentativa de analizar las causas históricas, sociológicas o económicas de la pobreza en América Latina» (Robin, 2004, p. 271).

A este periodo se le conoce como Guerra Sucia y abarcó en México tres sexenios presidenciales, los de Gustavo Díaz Ordaz (1964-1970), Luis Echeverría Álvarez (1970-1976) y José López Portillo (1976-1982). La Dirección Federal de Seguridad (DFS), que dependía directamente de la Secretaría de Gobernación y estaba conformada por policías de élite y militares, fue la encargada de llevar a cabo estas acciones. Entre sus principales funciones estaban hacer espionaje político e infiltración, desarticular los grupos subversivos, acosar a opositores e incluso a miembros del propio régimen para asegurarse de mantener el control gubernamental (López de la Torre, 2013). Para cumplir con su misión, los agentes de la DFS recurrieron a la perpetración de crímenes que se consideran de lesa humanidad como las ejecuciones extrajudiciales, la 
tortura, las desapariciones forzadas, etc. (Aguayo, 2014; Castellanos, 2009; Comverdad, 2014; FEMOSPP, 2006; Montemayor, 2010; Scherer y Monsivais, 1999).

Entre las acciones contra-insurreccionales que cometían las fuerzas del Estado, además de los crímenes de lesa humanidad, estaban las detenciones arbitrarias prolongadas de las personas disidentes directamente implicadas en el movimiento armado, las cuales también se practicaban con aquellas personas sospechosas de ejercer acciones que pusieran en peligro la estabilidad del régimen a causa de sus posicionamientos políticos ${ }^{3}$. En 1961, Amnistía Internacional definió como prisionero de consciencia a «Toda persona a la que se le impide físicamente (por prisión u otras causas) expresar (por palabras o símbolos) la opinión que mantiene honestamente y que no defiende ni justifica la violencia personal» (de Dios Vázquez, 2013, p. 1217). Muy cercano a este se encuentra el concepto de preso político: militantes — del movimiento armado o no-, que son privados de la libertad de manera arbitraria, sin haber cometido un delito tipificado y como consecuencia de sus ideas políticas que confrontan las estructuras de poder (p. 1217) ${ }^{4}$.

3 Cabe destacar que esta no era una práctica nueva. Desde el 14 de noviembre de 1941, durante la presidencia de Manuel Ávila Camacho (1940-1946), se había promulgado la Ley de "Delito de disolución social», la cual tenía por objeto reprimir y encarcelar a los disidentes políticos. Sin embargo, interesa señalar que, a pesar de que el régimen de Ávila Camacho no era simpatizante de la izquierda, el delito de disolución social no fue ideado para la izquierda, sino con el objetivo de neutralizar a simpatizantes de la derecha fascista que, en el marco de la Segunda Guerra Mundial, expresaban su apoyo a las potencias del Eje (Alemania, Italia y Japón). Al final de la Segunda Guerra Mundial, el recurso al Delito de disolución social cayó en desuso, pero, en el marco de las administraciones de Adolfo López Mateos (19581964) y Gustavo Díaz Ordaz (1964-1970), retomó fuerza como herramienta legal para amedrentar a los movimientos disidentes; particularmente eran vinculados a este delito los detenidos que esperaban sentencia en Lecumberri. Como parte de las negociaciones posteriores a la matanza de estudiantes de 1968 y del 10 julio de 1970, en el mismo mes de julio de 1970, Gustavo Díaz Ordaz emitió un decreto constitucional por el cual se derogaban los artículos 145 y 145 bis del Código Penal Federal, relativos al Delito de disolución social (de Dios Vázquez, 2013).

4 En 2012, la Asamblea Parlamentaria del Consejo Europeo definió cinco características para que una persona pueda ser considerada como prisionera o prisionero 
En ese sentido, las acciones represivas de las fuerzas del Estado no solo estaban destinadas a los integrantes de los grupos disidentes, sino que también se extendieron a las y los familiares de los miembros de estos grupos - aunque no tuvieran ningún tipo de participación en el movimiento- e incluso a comunidades rurales enteras sospechosas de apoyar a la guerrilla (Guzmán y Pimentel, 2011; Radilla y Rangel, 2012). La Base Militar 27 en Atoyac, Guerrero; la Base Aérea n. ${ }^{\circ}$ 7, Pie de la Cuesta, Guerrero; la Base Naval de Icacos en Acapulco Guerrero, y principalmente El Campo Militar n. ${ }^{\circ} 1$-el más grande centro clandestino de detención y tortura de la historia de México (Castellanos, 2009, p. 157) - , serían los centros de detención clandestina por excelencia (FEMOSPP, 2006). Sin embargo, según la FEMOSPP, también había centros de detención que no dependían directamente del ejército, como el centro de reclusión masculina de Lecumberri, conocido como el Palacio Negro, donde además las personas eran retenidas de manera clandestina y se practicaba la tortura; en consecuencia, surgiría el primer comité de familiares en la defensa de los presos perseguidos y exiliados políticos en México.

Muchos de los presos políticos que se internaban en Lecumberri habían pasado ya por los centros clandestinos de reclusión militar donde habían sido sometidos a actos de tortura. Blanca Hernández, una de las fundadoras del Comité de Familiares de Presos, Perseguidos y Exiliados Políticos, lo expresa de esta manera:

político. Según esta instancia, se considera prisionera o prisionero político: a) si la detención se hizo violando una de las garantías fundamentales establecidas en la Convención Europea de Derechos Humanos y sus Protocolos (ECHR), en particular la libertad de pensamiento, conciencia y religión, libertad de expresión e información, libertad de reunión y asociación; b) si la detención fue impuesta por razones puramente políticas sin conexión con ningún delito; c) si, por motivos políticos, la duración de la detención o sus condiciones son claramente desproporcionadas con el delito del que la persona ha sido declarada culpable o sospechosa de serlo; d) si por motivos políticos la persona es detenida de manera discriminatoria en comparación con otras personas; y, e) si la detención es el resultado de procedimientos claramente injustos y esto pudiera estar relacionado con motivos políticos de las autoridades (Parliamentary Assembly ce, 2012). 
Ya venían de tortura porque los detenían y era una desaparición temporal en el Campo Militar n. ${ }^{\circ} 1$ o en las diversas cárceles clandestinas. La tortura que recibían allá: todo. Eso del pocito, los toques eléctricos, además de los golpes. Todo eso para que hablaran y delataran a más compañeros. (Entrevista del 9 de febrero del 2017)

En Lecumberri, si las condiciones eran precarias para la mayoría de las personas recluidas (García, 2015), para los presos «subversivos» estas se radicalizaban, ya que eran sometidos a toda clase de vejaciones en las que las garantías individuales y los derechos humanos quedaban suspendidos. En palabras de Blanca Hernández:

Venían «recomendados». O sea, con ellos había que ser más duros todavía, que con los comunes. Entonces les hacían una cosa que le llamaban el chocho. Ponían a los que venían como presos políticos de la lucha armada a que los levantaran en la madrugada, 3:00 de la mañana, para que estuvieran con un ladrillo tallando el piso hasta que se deshiciera el tabique como para tenerlos ahí con el frío, en calzones nada más, y echándoles agua fría, poniéndolos a que lavaran las letrinas veinte mil veces. O sea, los peores trabajos más vejatorios. (Entrevista del 9 de febrero del 2017)

La prisión estaba dividida en varias crujías. En la $M$, por ejemplo, tenían concentrados a muchos de los estudiantes del movimiento de 1968. En la $O$, a los militantes de la guerrilla que consideraban de mayor «peligrosidad». Lecumberri estaba destinado a ser un reclusorio preventivo, una vez que la sentencia fuera dictada, los detenidos tendrían que ser trasladados a los centros penitenciarios, pero en realidad muchos de quienes eran internados en este centro, permanecían por varios años, en particular los presos políticos. Por ejemplo, el 25 de enero de 1972, miembros de la Brigada Blanca detuvieron arbitrariamente en la Ciudad de México - bajo tratos crueles, inhumanos y degradantes - a Lourdes Uranga López y Roberto Tello Alarcón, ambos miembros del Frente Urbano Zapatista (Fuz). Dos años después, cuando surgió el Comité, 
la sentencia de este último aún no había sido dictada y continuaba en reclusión «preventiva».

Dado que en la guerrilla tenían por consigna mantener su participación en la clandestinidad, ni siquiera las personas más cercanas conocían su actividad en estos grupos. Tal fue el caso de Blanca Hernández, estudiante de Medicina en esa época, que se enteró por el periódico de que su pareja, Roberto Tello Alarcón, había sido detenido, acusado de estar vinculado con la guerrilla urbana:

Yo no sabía. Ah, pues cuando estaba precisamente haciendo yo lo del servicio social, como estaba por allá en la montaña, bajé al pueblo a buscar periódicos y que veo en el periódico, pues la foto del galán que estaba en uno de los grupos armados que había en la ciudad de México. ¡Qué barbaridad, ahora voy a tener que ir a hacer visitas a Lecumberri! (Entrevista del 12 de diciembre del 2017)

Podemos afirmar que el Estado mexicano había determinado ejercer un «estado de excepción» no declarado a quienes consideraba sus opositores políticos, a través del cual la observación del respeto de los derechos humanos por parte de las fuerzas públicas y castrenses quedaba suspendida. Los prisioneros políticos eran constantemente sometidos a tortura. Sus procesos judiciales estaban detenidos por lo que su reclusión transcurría en la ilegalidad. Es así que familiares de algunos de estos presos internos de Lecumberri, principalmente mujeres, decidieron organizarse. En un primer momento reclamaban mejores condiciones de reclusión y el debido proceso de quienes se consideraban como presos políticos, pero pronto ampliarían su marco de acción al de la restitución de los derechos de quienes habían partido al exilio en el marco de esta represión y la anulación de las órdenes de aprehensión de los perseguidos políticos. Como lo veremos más adelante, los cambios políticos crearon una cierta oportunidad política (McAdam, Tarrow y Tilly, 2001), que permitió a las defensoras de prisioneros políticos pasar de 
la organización de acciones centradas en la defensa de sus familiares a una movilización más amplia en defensa de los derechos humanos.

\section{Las mujeres en defensa de los presos, exiliados y perseguidos políticos}

Esta segunda sección está centrada en la acción de las mujeres del Comité en el marco de la defensa de los derechos humanos. Abordaremos tres dimensiones de este proceso: lo que les motiva a organizarse, cómo deciden salir de la esfera privada a la lucha pública contra las violencias de Estado y el reclamo de un debido proceso para sus familiares, así como los desafíos organizativos y obstáculos a los que se enfrentaron. Nos interesa destacar que las mujeres reaccionaron a un sentimiento de injusticia, debido a que sus compañeros estaban recluidos en condiciones arbitrarias y eran constantemente sometidos a tortura y tratos crueles e inhumanos; a su vez, al momento de visitarlos, ellas mismas eran sometidas a vejaciones.

En un primer momento la demanda estaba enfocada en acelerar los procesos judiciales, para lo cual las acciones se dirigieron a encontrar una representación legal adecuada, a ejercer presión sobre el procurador de la República y el poder ejecutivo, así como a sensibilizar a diputados y a los partidos de oposición. En la medida en que se fueron organizando y en reacción a las interacciones mismas con los órganos de Estado, ampliaron su marco de acción y, posteriormente, reivindicaron el respeto a los derechos humanos y a las garantías individuales de los presos políticos como sujeto colectivo. Así mismo, lograron garantizar las condiciones para que los exiliados políticos pudieran volver y para que se detuviera la persecución de los luchadores sociales.

En el marco de la organización del Comité se dio un cambio importante en los liderazgos de género en la defensa y reivindicación de derechos. Si en la gran mayoría de los movimientos sociales de la época, los líderes y dirigentes eran hombres, en el marco de la defensa de los derechos 
humanos, la mayoría fueron mujeres. Esto se explica por las dinámicas de género en sí mismas, puesto que la defensa de derechos humanos tiene una dimensión importante del cuidado del otro o de la otra, que en este caso pasaba por la defensa de sus familiares, quienes, al ser prisioneros de conciencia no podían emprender acciones de defensa por ellos mismos. Destacamos que esta relación no estuvo exenta de sexismo tanto en su interacción con los prisioneros políticos como con sus aliados, quienes denostaban las acciones e iniciativas de las integrantes del Comité.

En razón a lo anterior, podemos analizar que una de sus tácticas de «des-sujeción» fue el hecho de tener que negociar en torno a las dinámicas de género con los presos mismos y sus aliados en el marco de este movimiento. Además, otro de los retos a los que se enfrentaron como Comité fue a la resistencia de los mismos presos a entablar un diálogo con los órganos de gobierno, puesto que el Comité y la lucha armada respondían a racionalidades distintas: las primeras abogaban por un trato digno y por el respeto del Estado de Derecho, los segundos, por cambiar las condiciones estructurales de pobreza y marginación. Finalmente, estudiaremos también las diferentes estrategias del Estado para debilitar al Comité, a las cuales debieron hacerle frente, por ejemplo, el hostigamiento constante, la separación geográfica de los presos para dificultar la organización o, incluso, la anticipación de la salida de prisión de algunos presos cuyas familiares demostraban un liderazgo importante en las reivindicaciones colectivas, con lo cual lograban separarlas del grupo, con base en las mismas reglas que ellas se habían autoimpuesto: una vez que su familiar saliera libre, podrían tener voz pero no voto.

\section{Lo que motiva las mujeres a organizarse}

Luego de varios años de visitas consuetudinarias a la cárcel —en algunos casos diarias - y de que aumentara el sentimiento de impotencia al ver que los procesos judiciales no avanzaban y, por lo mismo, que las posibilidades de que salieran de prisión sus familiares eran ínfimas, 
fue que las mujeres decidieron movilizarse. En palabras de Blanca Hernández: «Nos teníamos que organizar, simplemente para pedir que se movieran los expedientes, que no hubiera esas situaciones tan terribles. Todo, de comida, de todo. Era horrible» (entrevista del 12 de diciembre del 2017). Aunado a lo anterior, las acciones vejatorias no estaban únicamente destinadas a los presos políticos, sino a ellas mismas, las mujeres que les visitaban:

Todo nos revisaban, le metían palos sucios a la comida y dejaban pasar lo que querían. Y luego de eso pasábamos a los cuartos donde estaban las mujeres policías y nos revisaban todo. Querían casi que alzáramos las faldas. No podíamos ir de pantalones, no botas. Querían meter la mano debajo de la falda. Claro, uno rechazaba todo eso. Horrible, eran vejaciones. Las de la O estábamos más controladas, por eso comenzó ahí la organización, ya no aguantábamos eso, por eso es que decidimos organizarnos. (Entrevista del 12 de diciembre del 2017)

Estas mujeres empezaron a hablar con los familiares de los presos políticos con los que coincidían durante los días de visita en Lecumberri. Como lo cuenta Blanca Hernández: «Entonces decidimos, pues, hablar. Nos esperamos, nos salimos un poquito antes y nos esperamos para ver a las familias y hablarles y decirles que nos teníamos que organizar» (entrevista del 12 de diciembre del 2017).

A partir de ahí, las mujeres fueron creando una red a través de la cual se movilizarían para sus acciones "Ahí estuvimos convenciendo a las madres, a las hermanas, las novias, a las parejas» (entrevista del 12 de diciembre del 2017). Según Blanca Hernández, así nació el primer Comité de Familiares de Presos, Perseguidos y Exiliados Políticos de México en el transcurso del año de 1973. Este fue constituido en un primer momento por mujeres jóvenes que eran parejas, novias o esposas de los presos políticos: «Realmente éramos como cinco las que iniciamos: Blanca Hernández, estudiante de Medicina; Rosario, quien era obrera; Elsa Lecuona, quien era abogada; Tere, quien era estudiante de 
derecho y Lourdes, quien era diseñadora» (entrevista del 12 de diciembre del 2017). Cuatro de las cinco contaban con formación universitaria, algo que significaba en sí mismo un cierto estatus, ya que, en aquella época, las mujeres representaban apenas el $17 \%$ en la matrícula de la educación superior del país (de Garay y del Valle, 2012, p. 5). Algunas de ellas, como Blanca Hernández, tenían su propia trayectoria de participación política; por ejemplo, ella había formado parte del movimiento estudiantil de 1968 y había participado en diversas movilizaciones en su propia Facultad de Medicina.

Si en la época la gran mayoría de los movimientos sociales estudiantiles habían estado liderados por hombres, los comités de familiares de defensa de los derechos humanos serían liderados por mujeres. Esto obedece a que, si bien los comités jugaban en la escena de lo político, la defensa de los derechos humanos estaba asociada a una dimensión del cuidado del otro. Las dinámicas de género explican, en parte, por qué las mujeres jugaron un rol de primer plano en esta lucha. La implicación política en torno de la defensa de los presos políticos surgió, así, de un acompañamiento cotidiano de sus compañeros en situación de reclusión. Como lo dice Blanca Hernández: «Yo iba diario. Estas cinco [se refiere las fundadoras del Comité] éramos de las de 365 días al año, diario, diario, por eso apoyábamos a todos los demás, conocíamos a todos, ayudamos a todos los demás que no tenían familiares» (entrevista del 13 de diciembre del 2017).

Al principio, coincidían a la salida de las visitas y ahí se preguntaban por el estatus de los casos de sus compañeros, cómo iban sus procesos, entre otras cosas, y así se fueron organizando:

Entonces a la salida, los días de visita, nos quedábamos ahí preguntándoles a las que conocíamos «ay, itú de quién eres familiar? Sí, mira, qué vamos a hacer para que se muevan». Ahí estuvimos convenciendo a las madres, a las hermanas, las novias, a las parejas y luego tratar de encontrar a la gente de la [crujía] M. También en la salida, a ver quién es familiar de 
preso político, quién sabe qué y quién sabe cuánto y bueno así y ya ¿no? Y luego tomamos varias decisiones. Realmente éramos como cinco. (Entrevista del 13 de diciembre del 2017)

A partir de ahí, el Comité se ampliaría, siempre constituido principalmente por mujeres, muchas de las cuales acudían de manera intermitente, pero otras, madres en su mayoría, mantuvieron una actividad constante como las señora Castañeda y la señora Zavala, quienes tenían tres hijos recluidos cada una; la señora Salcedo; doña Agustina; Eva Loperena, que era hermana de un recluido; las hermanas Romero, que eran originarias de Oaxaca y también tenían un hermano en la misma situación; el señor Estrada; el señor Moreno; la pareja Rentería, originaria de Guadalajara, quienes tenían un hijo preso y, paralelo al Comité de la Ciudad de México, junto con otras mujeres - Mariquita Morales, Chela López y doña Petus- comenzaron a formar un comité en Jalisco (Castellanos, 2009, p. 307).

\section{De lo cotidiano a la lucha contra las violencias políticas}

Una vez organizados como comité, las y los integrantes elaboraron varios acuerdos originados por la desconfianza ante un Estado que tenía una larga tradición de infiltración de los movimientos sociales y de cooptación de sus líderes (Aguayo, 2014). El primer acuerdo dictaba que sus acciones se harían a título colectivo, no se reivindicarían casos individuales: «nadie podía hablar por su familiar, todas teníamos que pedir por todos, porque había muchos compañeros que venían de lejos, que sus padres o familiares no tenían dinero para visitarlos» (Blanca Hernández, entrevista del 13 de diciembre del 2017). El segundo acuerdo estimaba que, una vez que su familiar saliera libre, las personas podrían seguir apoyando las acciones del Comité, en el cual tendrían voz, pero no voto. En la misma entrevista, Blanca Hernández nos aclara:

Si por alguna cosa, alguno de nuestros familiares salía, podíamos seguir apoyando al Comité, pero nosotros ya no teníamos voz, apoyábamos, pero 
no decidíamos. Porque no se diera malentendido, de que tú vienes a decir aquí qué se tiene que hacer porque ya te compraron. Entonces, queríamos ser, como de mucha ética, ¿no? Y así lo hicimos.

A partir de esta primera iniciativa de organización, vendría un largo proceso de constitución de estas actrices como sujeto político (Samaddar, 2014). Dado que la conformación como colectivo fue motivada por la ausencia del debido proceso en la detención de sus compañeros y de las vejaciones a las que estos eran sometidos, al igual que ellas al momento de las visitas, la primera línea de batalla que emprendieron fue la jurídica. Pero, para esto, el comité buscó en primera instancia el apoyo de abogados. En palabras de Blanca Hernández:

Porque, si no, ¿cómo se iban a mover los procesos, si no teníamos abogados? Empezamos a visitar varios abogados, nadie nos quería ayudar, hasta que llegamos con unos refugiados de la República española, Carlos Fernández del Real, y él trabajaba junto con el licenciado Guillermo Andrade Gressler. Entonces ellos fueron nuestros abogados. (Entrevista del 9 de febrero del 2017).

Una vez que contaron con el apoyo de abogados, la estrategia apuntó en dos sentidos. El primero fue localizar a más familiares de los presos políticos para convencerlos de que se unieran al Comité. El segundo fue mantener una presión constante hacia funcionarios públicos de los poderes Ejecutivo, Legislativo y Judicial en y fuera de sus oficinas, en eventos públicos o en lugares donde sabían que se iban a presentar. Luego de varios meses de antesala, lograron finalmente obtener una cita con el Procurador General de la República, Pedro Ojeda Paullada (1971-1976), quien les pidió que elaboraran una lista de todos los presos que ellas reivindicaban como presos políticos y decían representar.

Entonces bueno, así pasó el tiempo y por fin nos recibieron. El tipo cuando nos recibió empezó así de: "A ver, señora, dígame, ¿quién es su hijo?». Y la señora: «Yo no estoy aquí por mi hijo, yo estoy aquí por todos». Otra: «Yo no estoy aquí por nadie, estoy por todos». Y luego, caímos en la 
provocación, nos dijo que a quiénes representábamos. Y nosotras todavía le dijimos que representábamos a todos los presos [políticos], que eran los familiares de todos los presos políticos del país. ¡Bastante exageradas! Y nos dijo: "iAh, sí?, pues entonces quiero nombre y apellido y el número de proceso de cada uno de ellos». [...] Bueno, el caso es que hicimos las listas. Lo que se hizo es que, a ver: «iDe dónde viene tu mamá o tu hermana o tu novia?». «De Tamaulipas». «Órale, te me vas a Tamaulipas y ves qué penal hay y si hay presos políticos. Ah, y tú, de Guadalajara a Oblatos. Y tú, de Oaxaca, pues...». Y así, realmente formamos el Comité nacional. (Blanca Hernández, entrevista del 16 de marzo del 2017)

Fue a partir del trabajo de elaboración de esta lista que el Comité realmente tomó una envergadura nacional. La respuesta del Estado hizo que las y los familiares se organizaran a nivel nacional para recopilar los nombres de los presos políticos, muchos de los cuales se negaban a revelar su verdadera identidad. Es decir, el requerimiento institucional, que pudo haber sido pensado como una estrategia dilatoria, de obstrucción o de negación, les fortaleció.

Desde los inicios del Comité, las integrantes habían intentado en varias ocasiones, incluso de varias maneras, obtener una cita para una reunión como colectivo con el presidente de la República mexicana, primero con Luis Echeverría Álvarez (1970-1976) y luego con José López Portillo (1976-1982). Sin embargo, el gobierno mexicano practicaba una política de doble rasero: mientras que, en el mandato de Echeverría Álvarez, este le abría las puertas a los exiliados políticos de Centro y Sudamérica (Castellanos, 2009, p. 157; Keck y Sikkink, 2000, p. 158-159), nunca aceptó recibir al Comité de familiares, aun cuando sus integrantes fundadoras idearon diversas acciones para lograr acercarse a él. Como lo recuerda Blanca Hernández, a Echeverría se le estuvo siguiendo para presionarlo para mover los casos:

Esa vez, él iba al Museo de Antropología e Historia. Iba caminando en la explanada y lo tomé así [del brazo]. Y yo no lo soltaba. Y me dice, «ay bueno, 
está bien. Déjeme sus datos y la localizamos». Unos guaruras, ya que íbamos saliendo de ahí, me sofocaron, me tomaron de los dos brazos y así como un avioncito me sacaron y por supuesto que nunca jamás nos llamó ni hizo nada ni nada. (Entrevista del 13 de diciembre del 2017)

Establecer la reunión con López Portillo no fue tan difícil, ya que hubo un cambio en el contexto político y con este se creó una oportunidad política. Debido a que López Portillo llegó al poder casi como candidato único, porque el régimen priista no había aceptado el registro de los otros candidatos propuestos para la contienda y el descontento generalizado de las otras fuerzas políticas por la represión extendida a luchadores sociales, en su programa de gobierno se comprometió a dos acciones prioritarias: la reforma política y la ley de amnistía. No obstante, en los hechos continuó con la Guerra Sucia y la reforma política permitiría el registro ante el órgano electoral de los partidos de oposición, hasta ese momento inexistente. Por su parte, la ley de amnistía facultaría el regreso de los exiliados, la liberación de los presos políticos y la suspensión de las órdenes de aprehensión de quienes formaban parte de la guerrilla y no habían incurrido en delitos mayores como el asesinato o el secuestro (FEMOSPP, 2016, p. 496). En ese marco, en sus primeros meses de gobierno, aceptó recibir al Comité en una sesión de quince minutos, la cual no podría ser grabada y a la que podrían entrar solo 30 representantes. Como lo menciona Blanca Hernández, esta cita llegó después de un largo proceso de organización:

Entonces viene el cambio, cuando me dicen, ipor qué no hacemos una solicitud de entrevista con López Portillo? Y mira, ya habíamos hecho tantas cartas y solicitado tanto que hacer una carta más (...) ha de haber sido como en abril del 77. Ya fíjate cuántos años llevábamos y ellos cuántos años en la cárcel. Y entonces que llaman y que nos dicen que tenemos audiencia tal día con el presidente allí en los Pinos. Ya éramos Comité nacional, porque ya teníamos gente en diferentes estados, [pero] que solamente podían entrar 30 personas. Entonces quedamos de que nada más iba a hablar el expreso político, también de la lucha armada, e iba a hablar 
yo, así rapidísimo y el que queríamos que hablara más era el presidente, porque eran 15 minutos. (Entrevista del 14 de diciembre del 2017)

Estas mujeres decidieron afrontar al Estado y ocupar un lugar en la arena pública. Pasaron de una reivindicación que podría ser solamente individual - la aceleración de los procesos de sus familiares y compañeros - a demandas que se inscribían en el orden de lo público y, como sujetos colectivos, exigían el respeto al debido proceso por parte del poder judicial, la mejora de las condiciones de reclusión y las garantías individuales tanto de los presos políticos como de los familiares que les visitaban en prisión. Con este objetivo, recurrieron a alianzas estratégicas con los partidos políticos de oposición y abogados sensibles a la defensa de los derechos humanos debido a su trayectoria personal —exiliados políticos de la República española-, a fin de ejercer presión sobre el titular de la Procuraduría General de la República. Al no obtener una respuesta satisfactoria por parte de este último, la estrategia fue dirigirse hacia el titular del Poder Ejecutivo; para las integrantes del Comité, en un régimen presidencialista en el que no se observaba el Estado de derecho, esta era una de las pocas personas que podría darles una resolución efectiva.

\section{Desafíos organizativos y obstáculos}

Si bien el Comité de Familiares de Presos, Perseguidos y Exiliados Políticos fue pionero en la defensa de los derechos humanos en México, este no estuvo exento de desafíos, tanto en la organización interna como hacia el exterior: desde la resistencia de los presos, en cuanto a las estrategias de acción, el sexismo hacia las mujeres del Comité por parte de los presos y los partidos de izquierda, hasta las estrategias por parte del Estado para desarticular el proceso organizativo.

A nivel interno, el Comité se enfrentó a resistencias por parte de los presos en cuanto a las estrategias de acción. El proceso fue complicado y con muchos bloqueos por parte de los presos políticos debido a que el 
Comité de Familiares en Defensa de los Derechos Humanos se inscribía en una racionalidad distinta a la de los grupos guerrilleros. Estos últimos consideraban que las reivindicaciones del orden de los derechos humanos eran secundarias ante la prioridad que ellos imponían a sus reivindicaciones de la lucha armada. Por esta razón, lograr que las víctimas directas aceptaran el acompañamiento de sus familiares en defensa de sus derechos fue una tarea compleja:

¡Nuestros compañeros! Ellos no se metían, porque ellos no iban a «transar», ellos no querían amnistía, no querían nada. Ellos se habían metido a lo que se habían metido porque había que hacer cambios y nosotros no estábamos «transando» con nadie, queríamos dignidad, simplemente. Queríamos un proceso justo, nunca jamás [transar]. (Blanca Hernández, entrevista del 12 de diciembre del 2017)

Mientras que el Comité tenía como objetivo hacer valer las garantías individuales de cada uno de los presos políticos, los miembros del movimiento armado socialista mexicano tenían por consigna la renuncia a su individualidad por una causa más allá de su propia subjetividad: «Tuvo que ir el abogado Carlos Fernández a hablar allí a la $O$ con todos y decirles que se dejaran de ser niños y que en lugar de llamarse Puma dijera cómo se llamaba, ¿no?» (Blanca Hernández, entrevista del 13 de diciembre del 2017).

Frente a la dificultad de que los presos políticos aceptaran el acompañamiento, las mujeres movilizaron «tácticas de des-sujeción» con el objetivo de hacerle frente al sexismo al que se enfrentaban para, por un lado, reivindicar su lugar como mujeres en esta lucha, y por el otro, poder llevar avante la misión que se propusieron como Comité. Por esta causa, se organizaron entre ellas sin tener en cuenta el posicionamiento de sus familiares y compañeros, a pesar del machismo al que se enfrentaron, el cual provenía tanto de los presos mismos, como de los aliados que las apoyaban en el proceso. Blanca Hernández recuerda una de las formas que tomó este sexismo por parte de los presos políticos: 
Coordinábamos a todas: "Ay, tú, habla con esta», "tú consigues las mamás». Y, luego, cuando ellos [los presos políticos] supieron esto, entonces les prohibieron a las mamás que se juntaran con nosotros, pero pues ahí, ahí dentro de la cárcel: «hola, hola, buenos días» y ya, pero ya a la salida nos juntábamos: «Ay, hay que hacer». «Y mi hijo dice que no, pero yo sí voy». Claro que sí iba, pues, ¿no? Les veíamos la cara, ni modo. Y entonces fue ahí en la $O$, hacían un periódico mural. Entonces hicieron un periódico mural y nos pusieron la UVA. Unión de Viejas Argüenderas. Entonces, ¡estábamos!, ahora ya me río, pero estábamos, enojadas. Con todo este rollo de las mujeres [el feminismo], enojadas, pero ya ahora me río. Hay todavía compañeras que se enojan, pero bueno. (Entrevista del 13 de diciembre del 2017)

Este sexismo se manifestó también a nivel externo cuando el Comité buscó el apoyo de los partidos de oposición, las mujeres tuvieron que resistir para que no se les excluyera de la toma de la palabra pública:

Nosotros, para tener más gente, nos acercamos a los entrecomillados partidos de izquierda y luego nos ponían a trabajar, a repartir las invitaciones para hacer conferencias de prensa y luego los que hablaban eran ellos, porque nosotros «no sabíamos». Ellos eran «los políticos» y pues ya nos tenían bastante [cansadas], sí nos dimos un agarrón feo. Tuvimos que llamar a nuestro abogado, que fuera Fernández del Real a defendernos, porque ya no los soportábamos y en una de esas que iba a haber un mitin y estábamos ahí la bola de mujeres y precisamente ahí los del partido [dijeron]: «Necesitamos un buen orador», quién sabe qué y estábamos cansadas, pues dijimos «lo hacemos nosotras». Pues que la señora Castañeda, sin que le dijéramos «usted», que se levanta y que dice yo hablo. Uy, yo estaba, todas estábamos bien contentas y todavía nos dijeron: "Ay no, señora, necesitamos una oradora». Les dijimos «pues la señora tiene tres hijos [presos] y sabe más que ustedes, así es que hasta aquí llegamos». Y, entonces pues, viendo esto que todas nos ayudábamos, que ayudábamos a los compañeros, este, pues se dio esta unidad entre todas, todas nosotras, ¿no? Yo nunca pensé que la señora Castañeda dijera que iba a hablar. Y era de 
las que también sus hijos le habían dicho no andes con las UVAS. (Blanca Hernández, entrevista del 13 de diciembre del 2017)

Otro obstáculo al cual hicieron frente los integrantes del Comité fue cuando, en 1976, el presidente Echeverría le indicó a Sergio Ramírez, director del penal, que cerrara la prisión de Lecumberri. Los presos fueron trasladados a los reclusorios Norte, Oriente y Sur situados en lados opuestos de la ciudad. Si antes era relativamente fácil encontrarse durante los días de visita para organizar las acciones y darles seguimiento a los procesos, la dispersión entre reclusorios diferentes dificultó la tarea. Como lo menciona Blanca Hernández:

Cuando salíamos de Lecumberri y ahí nos veíamos todas y ahí cogíamos caminito para ir a ver a los abogados, para ver los procesos, para sacar todos los nombres de los compañeros, para ir viendo qué pasaba. O sea, nos era mucho muy fácil; lo hicieron para dividirnos. Además de que los días de visita ya no eran los mismos para todos. (Entrevista del 13 de diciembre del 2017)

Otro de los principales problemas que enfrentaron fue que, cuando había una persona, particularmente una madre, que destacaba por su elocuencia en el discurso o en sus habilidades oratorias, su familiar salía libre, supuestamente bajo fianza. Este beneficio individual otorgado les restaba fuerza a las reivindicaciones colectivas. En razón de lo anterior, y ante la desconfianza que tenían las integrantes del Comité sobre las acciones del Estado, desde sus inicios habían establecido que solo podrían tener voz quienes tenían aún un familiar preso, perseguido o exiliado. Paradójicamente, esto le dio ventajas al aparato represor para intentar desarticularlas:

La señora Agustina, de Michoacán, fue muy importante para nosotros porque era bien buena para hablar. Entonces hacíamos un mitin, porque queríamos conseguir ver al procurador o los diputados o todo eso y la mandábamos llamar. Era buenísima (...) y de repente entrecomillados salió 
bajo fianza [su hijo] y ya nos quitaron a nuestra oradora. A una de nuestras compañeras también, la abogada. Pero que ni pagaron realmente fianza, pero [supuestamente] salieron bajo fianza. (Blanca Hernández, entrevista del 12 de diciembre del 2017)

Por otra parte, dos de las lideresas del Comité, Blanca Hernández y Teresa Álvarez, estuvieron detenidas-desaparecidas alrededor de una semana (Proceso, 1977; Ulloa, 2007). La detención arbitraria fue ejecutada por miembros de la Brigada Blanca y las dos mujeres fueron interrogadas personalmente por Miguel Nazar Haro, el director general de la Dirección Federal de Seguridad (DFS): «Estaba Nazar directamente: “¿Sabes quién soy?”. “Pues sí”. “iY cómo sabes?”. “Porque leo los periódicos”. El caso es que decían que había un intento de fuga y que yo había metido [al reclusorio] los explosivos. Pues no». (Blanca Hernández, entrevista 13 de diciembre de 2017). Ambas fueron amenazadas para que dejaran de lado la defensa de los derechos de los presos políticos si querían evitar que miembros de su familia fuesen agredidos. De acuerdo con Blanca Hernández, el objetivo era disuadirlas de que se siguieran involucrando en la defensa de los derechos humanos:

Por eso, para meter miedo y que ya no siguiera uno haciendo nada. Porque me dijeron pobre de ti, y más que de mí, de mi familia. Porque sí, cuando amenazaron a mi hija. «La vamos a traer». Ahí sí me... perdí todo. Me dijeron: «Y pobre de ti donde vayas a hacer una declaración diciendo que te detuvieron». (Entrevista del 13 de diciembre del 2017)

Poco después de la detención-desaparición de Blanca Hernández, su compañero, Roberto Tello Alarcón, salió libre, incluso antes de la amnistía, y, de acuerdo a las mismas reglas mencionadas, ella no podía seguir teniendo una participación activa en la organización. Poco a poco las fundadoras del Comité se fueron replegando y surgieron nuevos liderazgos como el de Rosario Ibarra de Piedra, madre de Jesús Piedra Ibarra, quien había sido detenido-desaparecido por su implicación política en Monterrey, Nuevo León, en 1975. Con la llegada de este nuevo 
liderazgo, el repertorio de acción colectiva (Tilly, 2008) se modificó e integró las huelgas de hambre como protesta, entre otras, e incluso se cambió el nombre inicial de Comité de Familiares de Presos, Perseguidos y Exiliados Políticos por el de Comité Prodefensa de Presos, Perseguidos, Desaparecidos y Exiliados Políticos, para hacer una diferenciación con la organización inicial y los liderazgos que le estaban asociados. Sin embargo, este nuevo Comité también estaba constituido únicamente por familiares y la mayoría eran mujeres también.

Casi dos años después de aquella primera reunión con López Portillo, la amnistía seguía sin aprobarse a pesar de que el Comité nunca dejó de insistir con desplegados, mítines, reuniones con funcionarios públicos, etc. El 28 de agosto de 1978, 84 mujeres y cuatro hombres liderados por Rosario Ibarra tomaron la Catedral del Zócalo de la Ciudad de México y se declararon en huelga de hambre durante cuatro días, como medida de presión para acelerar el proceso de declaración de la amnistía prometida por López Portillo desde su toma de posesión como presidente de la República. Esta acción, por demás mediática, contribuyó de manera determinante a la aceleración de promulgación de la amnistía, la cual fue declarada un mes después, el 28 de septiembre de 1978 (Carrión, 2015; Maier, 2001).

Finalmente, interesa destacar que el comité no guardó en su momento una memoria gráfica o escrita debido al hostigamiento persistente del que fueron objeto. La decisión de constituirse como sujeto político estuvo marcada por un miedo constante de represión ante su implicación en la defensa de los derechos humanos, razón por la cual nunca daban sus teléfonos particulares; los abogados siempre fueron el enlace. Por lo mismo, este primer Comité no guardó ningún registro de sus acciones para una reconstrucción de la memoria. Blanca Hernández recuerda:

No hay fotos del Comité, no hay fotos de nosotros, ¡nada! ¿Por qué? Porque todo eso se iba a la policía y no sé qué. Entonces, dentro de esa situación como familiares, vivíamos con ese miedo, que nos seguían. A veces se 
dejaban ver, a veces no. Entonces eso hizo también que tuviéramos silencio durante muchos años. (Entrevista del 9 de febrero del 2017)

En ese sentido, el mecanismo de represión cumplió en parte su objetivo, ya que no quedó un testimonio perenne de esta primera fase de organización colectiva de la defensa de los derechos de los presos políticos. En consecuencia, resulta indispensable la recuperación del testimonio - además con perspectiva de género- de quienes fueron precursoras de estas defensas en los momentos más álgidos de violencia del Estado y de represión política, para rescatar la memoria y hacerle frente al mecanismo represivo, que operó en el pasado, pero que, en parte, debido a la impunidad, se reproduce en el presente.

\section{Conclusión}

A lo largo de este artículo se analizó cómo la defensa de los derechos humanos en México surgió de la autoorganización, tras una sensación prolongada de injusticia frente al tratamiento del que eran objeto los presos políticos, víctimas de las violencias de Estado. El objetivo primario de este proceso organizativo era abogar por un debido proceso de los prisioneros políticos y poco a poco se fue ampliando su marco de acción en cuanto a la denuncia de las violencias. El fin primordial era contribuir a la restitución de la dignidad de las víctimas, a través de diferentes demandas que buscaban acelerar los procesos y que se dictaran sentencias, se anularan las órdenes de aprehensión y se garantizara el respeto de las condiciones para que las personas exiliadas pudieran retornar, entre otros objetivos.

Por otra parte, las condiciones de interacción tanto en estos primeros comités de familiares como con el Estado quedaron latentes a posteriori para alertar sobre los posibles intentos de cooptación por parte del Estado y ofrecer las estrategias necesarias para tratar de evitarlo. Una de estas estrategias fue la imposición de que se podía tener voz, pero no voto si los implicados no eran directamente una víctima o familiar de 
una víctima; en la actualidad, ocurre de igual forma con los múltiples colectivos de familiares de víctimas de las violencias políticas, en particular de desaparición forzada, dada la repetición del ciclo de violencia que se vive en el país.

Asimismo, tal como ocurre en otros movimientos sociales, las dinámicas subyacentes de relaciones de poder no fueron ajenas a este proceso. De forma paralela a la reivindicación principal en cuanto al debido proceso de sus familiares y compañeros y la observancia de los derechos humanos de los presos, perseguidos y exiliados políticos, las mujeres del comité tuvieron que recurrir a tácticas de des-sujeción para lidiar con el sexismo prevaleciente entre sus compañeros mismos y algunos de los grupos de aliados. Solo así pudieron adelantar el objetivo principal del movimiento.

Finalmente, interesa destacar que los obstáculos y desafíos tanto internos como externos, las dinámicas de género y la represión por parte del aparato de Estado, aunados a las restricciones que las mismas integrantes del Comité se autoimpusieron, además del desgaste por la militancia prolongada de un pequeño grupo de personas, contribuyeron a que el primer comité se disolviera lentamente. No obstante, esta disolución cedió el paso a nuevas formas de organización que lograron permanecer más tiempo en la arena pública como en el caso del comité de familiares Eureka o de la Asociación de Familiares de Detenidos Desaparecidos y Víctimas de Violaciones a los Derechos Humanos en México (Afadem).

Sin duda, estas formas sucesivas lograron prolongarse en parte gracias a la labor precursora de este primer comité de la defensa de derechos humanos, cuando el movimiento internacional aún era incipiente. Si en la literatura este primer comité ha sido soslayado, es debido a que estas mujeres, por temor a mayores represiones o represalias, no guardaron elementos materiales para la preservación de la memoria. Por esta causa, la redacción del presente artículo tuvo por objetivo contribuir a este 
rescate de la memoria de los orígenes y del contexto sociopolítico en el cual surgió y evolucionó el movimiento por los derechos humanos en el país; así mismo, busca destacar el rol de las mujeres, en particular de estas mujeres, en la defensa colectiva de las víctimas de las violencias políticas en el marco de la Guerra Sucia en México.

\section{Bibliografía}

Aguayo Quezada, Sergio (2014). La charola: una historia de los servicios de inteligencia en México. México: Editorial Ink.

Ávila Carrillo, Enrique (2018). El jaramillismo. Voces de la educación, 3(6), 25-51.

Castellanos, Laura (2009). Le Mexique en armes. Montréal: Lux Éditeur.

Comverdad (2014). Comisión de la Verdad del estado de Guerrero. Chilpancingo, Guerrero. Recuperado de: http://congresogro.gob.mx/files/InformeFinalCOMVERDAD.pdf.

de Dios Vázquez, Juan (2013). Rejas, murallas y otras demarcaciones: David Alfaro Siqueiros y José Revueltas en «El Palacio Negro de Lecumberri». Historia Mexicana, 62(3), 1211-1265.

Fiscalía Especial para Movimientos Sociales y Políticos del Pasado (FEMOSPP) (2006). Informe histórico presentado a la sociedad mexicana: fiscalía especial FEMOSPP. México: Comité 68 Pro Libertades Democráticas A. C.

Florez Flórez, Juliana (2007). Tácticas de des-sujeción: disenso, subjetividad y deseo en los movimientos sociales. Relaciones de género en la red «Proceso de Comunidades Negras» del Pacífico colombiano. Athenea Digital. Revista de pensamiento e investigación social, 12, 397-402. Recuperado de: https:// doi.org/10.5565/rev/athenead/v0n12.439.

Garay, Adrián de y Gabriela del Valle-Díaz-Muñoz (2012). Una mirada a la presencia de las mujeres en la educación superior en México. Revista Iberoamericana de Educación Superior 3(6), 3-30.

García Mendoza, Jorge (2015). Memoria de las desapariciones durante la Guerra Sucia en México. Athenea Digital. Revista de Pensamiento e investigación social 15(3), 85-108. 
Guzmán Cruz, Abdallán y Julio Pimentel Ramírez (2011). Los mártires de la democracia. La larga lucha de una familia de la comunidad indígena de Tarejero por la verdad y la justicia. México.

Hincapié Jiménez, Sandra y Jairo Antonio López Pacheco (2016). Ciclos de movilización y crisis de derechos humanos. La acción colectiva de las ONG nacionales y los derechos humanos en México. Revista de Estudios Sociales, 56, 26-38.

Jelin, Elizabeth (2007). Víctimas, familiares y ciudadanos/as: las luchas por la legitimidad de la palabra. Cadernos Pagu, 29, 37-60.

Keck, Margaret y Kathryn Sikkink (2000). Activistas sin fronteras. México: Siglo XXI.

López de la Torre, Carlos Fernando (2013). Miguel Nazar Haro y la guerra sucia en México. Grafía 10(1), 56-72.

López Pacheco, Jairo Antonio (2015). El campo de las ONG de derechos humanos en México: recursos y agendas. El Cotidiano, 194, 97-106.

Maier, Elizabeth (2001). Las madres de los desaparecidos: ¿un nuevo mito materno en América Latina? Ciudad de México: Universidad Autónoma Metropolitana.

McAdam, Doug, Sidney Tarrow y Charles Tilly (2001). Dynamics of contention. Cambridge: Cambridge University Press.

Montemayor, Carlos (2010). La violencia de Estado en México: antes y después de 1968. México: Random House Mondadori.

Proceso (1977). Secuestran a esposas de presos políticos. Proceso. Recuperado de: https://www.proceso.com.mx/4609/secuestran-a-esposas-de-presospoliticos

Radilla Martínez, Andrea y Rangel Lozano, Claudia (2012). Desaparición forzada y terrorismo de Estado en México. México, D. F.: Plaza y Valdés.

Robin, Marie-Monique (2004). Escadrons de la mort, l'école française. París: La Découverte. 
Rodríguez Ramírez, Brenda (2011). La ciudadanía como experiencia en las madres de Eureka. En: Mujeres y ciudadanía en México: estudios de caso. Ciudad de México: Universidad Autónoma Metropolitana.

Samaddar, Ranabir (2014). La emergencia del sujeto político. Política Común 6. Recuperado de: http://dx.doi.org/10.3998/pc.12322227.0006.007

Scherer García, Julio y Carlos Monsivais (1999). Parte de guerra. México: Nuevo Siglo/Aguilar.

Somuano, María Fernanda (2010). Las organizaciones civiles: formación y cambio. En: Los grandes problemas de México. XIV Instituciones y procesos políticos. México: El Colegio de México.

Padilla, Tanalis (2008). Rural resistance in the land of Zapata: The jaramillista movement and the myth of the Pax-Priista, 1940-1962. Durham: Duke University Press.

Parliamentary Assembly CE (2012). The definition of political prisoner.

Tilly, Charles (2008). Contentious performances. Cambridge: Cambridge University Press.

Ulloa Bornemann, Alberto (2007). Surviving Mexico's dirty war: a political prisoner's memoir. Filadelfia: Temple University Press. 